\title{
Türkiye'nin Enerji İhtiyacını Tahmin Etmek için Jaya Algoritmasına Dayalı Yeni Hibrit Bir Yaklaşım
}

\author{
Ergun Uzlu ${ }^{*}$ \\ 1* Karadeniz Teknik Üniversitesi, Mühendislik Fakültesi, İnşaat Müh. Bölümü, Trabzon, Türkiye, (ORCID: 0000-0002-2394-179X), ergunuzlu@ktu.edu.tr
} (3rd International Congress on Human-Computer Interaction, Optimization and Robotic Applications June 11-13, 2021)

(DOI: $10.31590 /$ ejosat.949440)

ATIF/REFERENCE: Uzlu, E. (2021). Türkiye’nin Enerji İhtiyacını Tahmin Etmek için Jaya Algoritmasına Dayalı Yeni Hibrit Bir Yaklaşım. Avrupa Bilim ve Teknoloji Dergisi, (26), 96-99.

$\ddot{O} \mathbf{z}$

Bu çalışmanın temel amacı, Türkiye'nin enerji tüketimini tahmin etmek için tahmin gücü yüksek bir model geliştirmektir. Model yeni ve güçlü bir optimizasyon algoritması olan Jaya algoritması ve regresyon fonksiyonlarına dayalı olarak geliştirilmiştir. Regresyon fonksiyonu olarak lineer, hiperbolik, eksponansiyel ve ikinci derceden fonksiyon kullanılmıştır. Modelde gayri safi yurtiçi hasıla, nüfus, ithalat ve ihracat verileri bağımsız değişkenler olarak kullanılmıştır. Jaya yönteminin doğruluğu, ortalama rölatif hata, ortalama karesel hataların karekökü ve ortalama mutlak hata gibi hata kriterleri kullanılarak araştırılmıştır. Analizler sonucunda Jaya algoritması ile geliştirilen ikinci dereceden fonksiyonun diğerlerine göre daha iyi performans gösterdiği sonucuna varılmıştır. Optimal konfigürasyonlar tanımlandıktan sonra, Türkiye'nin gelecekteki enerji tüketim değerlerini tahmin etmek amacıyla bir senaryo geliştirilmiştir. Elde edilen sonuçlar önceki çalışmalarla karşılaştırılmıştır. Elde edilen sonuçlara göre, önerilen model kullanılarak Türkiye'nin birincil enerji tüketimi modellenebilir ve Jaya, Türkiye'nin gelecekteki enerji ihtiyacını tahmin etmek için kullanılabilir.

Anahtar Kelimeler: Enerji tüketimi/ihtiyac1, Jaya algoritmas1, Meta-sezgisel algoritma.

\section{A Novel Hybrid Approach Based on Jaya Algorithm to estimate Energy Need of Turkey}

\begin{abstract}
The main objective of this study is to develop a highly predictive model to forecast Turkey's energy consumption. The model has developed based on regression functions and Jaya algorithm which is a new and powerful optimization algorithm. Linear, exponential, hyperbolic and quadratic functions were used as regression functions. Gross domestic product, population, import and export data have been used as independent variables in the model. The accuracy of Jaya method was investigated using error criteria such as average relative error, root mean square error, and mean absolute error. As a result of the analysis, it was concluded that the quadratic function developed with Jaya algorithm performed better than the others. After the optimal configurations have been defined, a scenario has been developed to estimate Turkey's future energy consumption values. The obtained results are compared with the previous studies. According to the obtained results, primary energy consumption of Turkey can be modeled using the proposed model and Jaya can be used to predict Turkey's future energy need.
\end{abstract}

Keywords: Enery consumption/demand, Jaya algorithm, Metaheuristic algorithm.

\footnotetext{
*Sorumlu Yazar: ergunuzlu@ktu.edu.tr
} 


\section{Giriş}

Enerji yaşam kalitesinin yanı sıra ekonomik ve sosyal ilerlemenin sağlanması için en önemli faktördür. 2018 yılında Türkiye'nin toplam enerji tüketiminin \% 86's1 fosil yakıtlardan sağlanmıştır ve ilk üç sırada petrol (\% 29.16), doğal gaz (\% $28.65)$ ve kömür (\% 28.43) bulunmaktadır (ETKB 2019). Diğer taraftan doğalgazın\% 99'u, petrolün\% 89'u ithal edilmiştir (BOTAS 2015). Nitekim Türkiye ve dünyadaki fosil yakıt rezervleri son derece sinırlıdır. Fosil yakıtlar mevcut hızda kullanılırsa, 2030 y1lına kadar tükenecektir (Bordbari vd., 2018). $\mathrm{Bu}$ nedenle fosil yakıtların kaybedilmesi, gelecekte yıkıcı etkilere neden olabilir.

Gelecekteki enerji ihtiyacının belirlenmesi, fosil yakıt kullanımının dezavantajlarını azaltmak ve sürdürülebilir bir büyüme politikası sağlamak açısından son derece önemlidir. Tüm bu faktörler göz önünde bulundurularak, Türkiye'nin enerji ihtiyacını tahmin etmek için birçok faklı teknik kullanılmıştır. Regresyon analizi bu teknikler içerisinde en çok tercih istatistik yöntemlerden biridir. Ancak regresyon analizi bazı kesin matematiksel ifadelere dayandığından, bağımsız değişkenler ile bağımlı değişsen arasındaki ilişkiyi tam olarak modelleyememektedir. Regresyon analizinin bu eksikliğini gidermek için regresyon fonksiyonları genetik algoritma (GA), karınca kolonisi algoritması (ACO), parçacık sürüsü (PSO) ve ögretme-öğrenme tabanlı (TLBO) optimizasyon algoritması gibi yapay zeka algoritmaları ile kullanılarak hibrit modeller geliştirilmiştir. Örneğin: Öztürk vd. (2004), Canyurt vd. (2004), Ceylan ve Ozturk (2004) GA'yı, Toksarı (2007) ACO'yu, Unler (2008) PSO'yu, Tefek vd. (2019) TLBO'yu regresyon fonksiyonlarına uygulayarak Türkiye için hibrit enerji tüketimi tahmin modelleri geliştirmişlerdir. GA, ACO ve PSO gibi algoritmalar kendi özel kontrol parametrelerini barındırdığından kullanımları zordur. $\mathrm{Bu}$ zorluğun üstesinden gelebilmek için Jaya gibi sadece genel kontrol parametrelerine sahip metasezgisel algoritmalar geliştirilmiştir.

Jaya yeni, kullanımı kolay ve sağlam bir meta-sezgisel algoritmadır. Jaya yeni bir yöntem olmasına rağmen, mekanik, termal ve inşaat mühendisliği dahil olmak üzere çeşitli mühendislik alanlarında kullanılmıştır. Jaya yönteminin PSO, diferansiyel değerlendirme, yapay arı kolonisi (ABC) ve TLBO gibi diğer optimizasyon yöntemlerinden üstün olduğu önceki çalışmalarda (Rao 2016) belirtilmiştir.

$\mathrm{Bu}$ çalışmanın ana hedefi, gelecekteki ulusal enerji ihtiyacını belirleyebilmek için hibrit bir model geliştirmektir. Model Jaya algoritması ve regresyon fonksiyonlarının hibridizasyonundan oluşmaktadır. Modelde bağımsız değişkenler olarak Türkiye'nin sosyo-ekonomik göstergeleri seçilmiştir. Önerilen model ve senaryoya göre Türkiye'nin gelecekteki enerji kullanım değerleri belirlenmeye çalışılmıştır.

\section{Materyal ve Metot}

\subsection{Jaya Algoritması}

Tüm meta-sezgisel algoritmalar, popülasyon boyutu ve yineleme sayısı gibi ortak değerler gerektirir. Bunlara ek olarak, bazı algoritmalar kendilerine has parametrelere ihtiyaç duyar. GA, geçiş olasılığı, mutasyon olasılığı, seçim operatörü gerektirir; ABC algoritması arı sayısı (izci, izleyici ve çalışan arılar), limit gerektirir. Algoritmaların performansı, algoritmaya özgü kontrol parametrelerin doğru kullanımına bağlıdır. $\mathrm{Bu}$ nedenle, Jaya algoritması gibi daha az kontrol parametresine sahip optimizasyon algoritmalarının kullanılması daha çekici hale gelmektedir.

Son zamanlarda geliştirilen popülasyon tabanlı optimizasyon yöntemlerinden biri, yukarıda bahsedilen dezavantajları ortadan kaldırmak için 2016 yılında Rao (2016) tarafindan önerilen Jaya algoritmasıdır. Jaya algoritması, yalnızca popülasyon boyutu ve maksimum çevrim sayısı gibi ortak kontrol parametrelerine ihtiyaç duyar. Aynı zamanda, Jaya algoritması basit sayısal yapıya sahiptir. Bu nedenle, Jaya algoritmasının uygulanması ve kodlanması, diğer algoritmalara nispeten daha basittir. Dahası, Jaya diğer meta-sezgisel algoritmalardan farklı olarak yerel minimumda sıkışıp kalmaz. Jaya algoritmasının bu özellikleri onu diğer meta-sezgisel algoritmalardan daha üstün kılar.

Jaya algoritması için çevrim sürecinin adımları Şekil 1'de verilmiştir. İlk adımda rastgele bir başlangıç popülasyonu oluşturulur. Algoritma her zaman başarıya yaklaşmaya (yani en iyi çözüme ulaşmaya) ve başarısızlıktan uzak durmaya (yani en kötü çözümden uzak durmaya) çalışır. Bu şekilde tüm aday çözümler güncellenir.

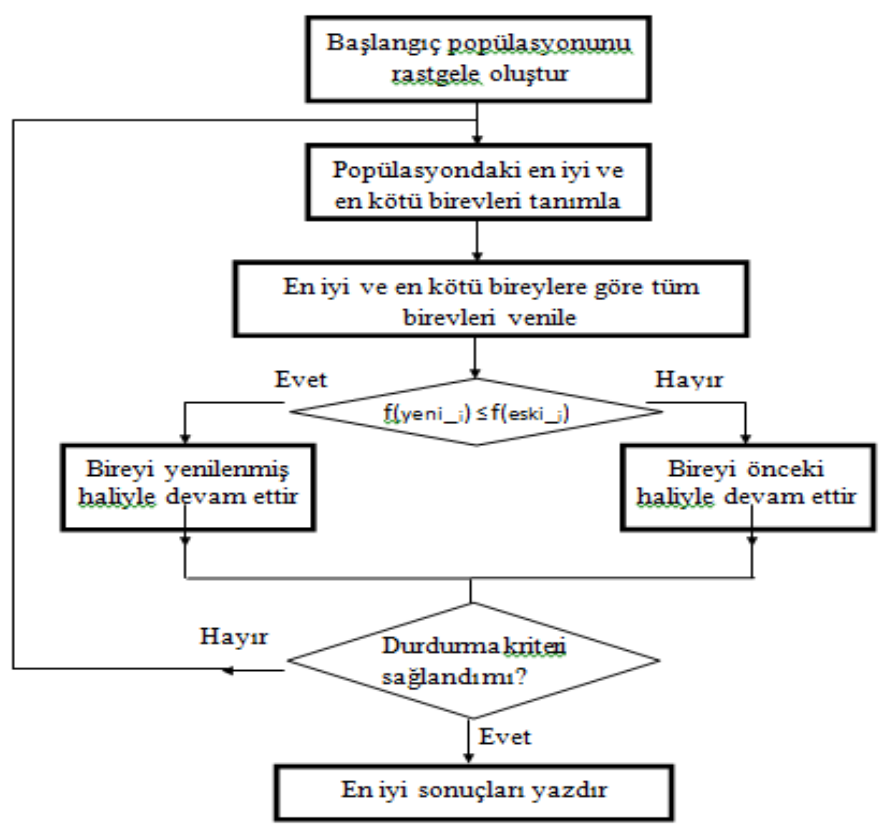

Şekil 1. JAYA algoritmasının akış diyagramı

\subsection{Enerji Tüketimi Tahmin Modelinin Geliştirilmesi}

Modelleme sırasında, gayri safi yurt içi hasıla (GSYİH), nüfus, ithalat ve ihracat verileri dikkate alınarak enerji tüketimini tahmin etmek amaciyla dört farklı regresyon fonksiyonu kullanılmıştır. Bunlar doğrusal fonksiyon (DF), hiperbolik fonksiyon (HF), eksponansiyel fonksiyon (EF) ve ikinci dereceden (IF) fonksiyondur. DF, HF, EF ve İF'nin genel formları önceki çalışmalarda (Uzlu vd., 2014) bulunmaktadır.

Jaya algoritması amaç fonksiyonun değerini minimuma indirgemek için bağımsız değişkenlerin $\left(x_{i}\right)$ katsayılarını $\left(w_{i}\right)$ optimize etmeye çalışır. Amaç fonksiyonu olarak modelde ortalama karesel hata $(\mathrm{OKH})$ seçilmiştir. Amaç fonksiyonunun değeri durdurma kriterine (maksimum çevrim sayısı) ulaşılıncaya kadar Jaya algoritması tarafından minimize edilmeye çalışılır. Amaç fonksiyonunun formülü aşağıdaki gibidir. 


$$
O K H=\frac{1}{n} \sum_{k=1}^{n}\left(y_{k}-o_{k}\right)^{2}
$$

Denklem 2'de $o_{k}$ ve $y_{k}$ sırasıyla tahmin edilen ve gerçek değerlerdir, $\mathrm{n}$ ise toplam veri sayısıdır. Ayrıca modelin performansını değerlendirmek için ortalama karesel hataların karekökü $(\mathrm{OKHK})$, ortalama mutlak hata $(\mathrm{OMH})$ ve ortalama rölatif hata (ort. RH) kriterleri kullanılmıştır. OKHK, OMH ve ort. RH değerlerinin formülleri önceki çalışmalarda (Uzlu vd., 2014) sunulmuştur.

Kontrol parametreleri tüm modellerde aynı değer seçilmiştir. Maksimum çevrim sayısı 5000 ve popülasyon büyüklüğü 50 olarak ayarlanmıştır. Regresyon fonksiyonlarının katsayıları $\left(w_{i}\right)$ için çözüm aralığı $[-1,1]$ olarak seçilmiştir. Kontrol parametreleri ayarlandiktan sonra, her regresyon denklemi için Jaya algoritması kullanılarak 30 bağımsız koşma gerçekleştirilmiştir.

\subsection{Veri Seti}

Bu çalıșmada, GSYİH, nüfus, dıș ticaret değerleri modellerin giriş verileri olarak kullanılmıştır. Veriler 2 bölüm olarak sınıflandırılmıştır. Eğitim seti için 1980-2007 yılları arasındaki veriler ve test seti için 2008-2018 arasındaki veriler kullanılmıștır. Nüfus ve dıș ticaret verileri TÜIKK (Türkiye İstatistik Kurumu)'den (TÜİK 2019a; TÜİK 2019b), Enerji kullanım verileri ETKB (Enerji ve Tabi Kaynaklar Bakanlığı) 'dan (ETKB 2019) ve GSYİH verileri TKB (Türkiye Kalkınma Bakanlığı)'ndan (TKB, 2019) temin edilmiştir. Modellerin eğitim sürecini kolaylaştırmak için veriler [0.1, 0.9] aralığına

\section{Araștırma Sonuçları ve Tartışma}

\subsection{Geliştirilen Modellerin Performansının Değerlendirilmesi}

Yapılan analizler sonucu her bir fonksiyon türü için elde edilen en iyi modeller aşağıda sunulmuştur.

$$
\begin{aligned}
y_{D F}= & -0.0252-0.0315 x_{1}+0.6836 x_{2}+0.1707 x_{3} \\
& +0.2112 x_{4} \\
y_{H F} & =x_{1}^{-0.0168} x_{2}^{0.8345} x_{3}^{0.1785} x_{4}^{0.0688} \\
y_{E F}= & -1+\exp \left(0.0124+0.0368 x_{1}+0.5552 x_{2}\right. \\
& \left.+0.0223 x_{3}+0.0968 x_{4}\right) \\
y_{I F}= & -0.0218+0.0947 x_{1}+0.5285 x_{2}+0.4484 x_{3} \\
& +0.0539 x_{4}-0.0548 x_{1} x_{2}-0.0964 x_{1} x_{3} \\
& -0.2664 x_{1} x_{4}+0.5122 x_{2} x_{3} \\
& -0.1717 x_{2} x_{4}+0.1159 x_{3} x_{4}-0.0973 x_{1}^{2} \\
& +0.0598 x_{2}^{2}-0.4280 x_{3}^{2}+0.3144 x_{4}^{2}
\end{aligned}
$$

İF, EF, DF ve HF için eğitim seti verileri kullanılarak hesaplanan $\mathrm{OKH}$ değerleri sirasiyla $1.752,3.681,2.652$ ve 2.383'dür. Hata değerlerinden görüldüğ̈̈ gibi $\mathrm{IF}$ gerçek değerlere diğer fonksiyon türlerinden daha çok yakınsamıştır. Test seti için hesaplanan hata değerleri ise Tablo 1'de sunulmaktadır. Hem eğitim hemde test seti için hesaplanan hata değerleri dikkate alındığında en iyi modelin en küçük hata değerlerine sahip olan İF'dir.

\begin{tabular}{|c|c|c|c|}
\multicolumn{4}{|c|}{ Tablo 1.Test seti için hesaplanan hata değerleri } \\
\hline IF & $\begin{array}{c}\text { Ort. RH } \\
(\%)\end{array}$ & $\begin{array}{c}\text { OKHK } \\
\text { (Mtoe) }\end{array}$ & $\begin{array}{c}\text { OMH } \\
\text { (Mtoe) }\end{array}$ \\
\hline EF & $\mathbf{0 . 8 0 6}$ & $\mathbf{1 . 1 1 9}$ & $\mathbf{0 . 8 7 4}$ \\
\hline DF & 1.251 & 1.675 & 1.415 \\
\hline HF & 1.285 & 1.790 & 1.495 \\
\hline
\end{tabular}

Türkiye'nin enerji tüketimi için Kiran vd. (2012) ve Tefek vd. (2019) tarafindan geliştirilen modellerin ort. RH değerleri sirasıly $2.77 \%$ ve $0.920 \%$ 'dir. Tüm ort. RH değerleri, önerilen modelin ort. RH değerinden daha büyüktür.

Geliştirilen IF modeli kullanılarak Türkiye'nin 2019-2030 dönemi enerji ihtiyacı tahmin edilmeye çalışılmıştır. Senaryoda kullanılan nüfus verileri TÜİK'den (TÜİK 2019a) diğer veriler ise gerçek büyüme oranları dikkate alınarak elde edilmiştir. GSYİH için $6.82 \%$, ithalat için $11.20 \%$ ve ihracat için $13.27 \%$ 'lik büyüme oranları dikkate alınmıştır. Önerilen model kullanılarak elde edilen enerji tüketim projeksiyonunun Tefek vd. (2019) tarafından önerilen projeksiyon ile karşılaştırılması Tablo 2'de sunulmaktadır. Sunulan projeksiyon ve Tefek vd. (2019) tarafından elde edilen değerlerin birbirine yakın olması geliştirilen modelin doğruluğunu artırmaktadır.

Tablo 2. Önerilen enerji tüketim projeksiyonun Tefek $v d$. (2019) tarafindan önerilen projeksiyon ile karşılaştırılması

\begin{tabular}{|c|c|c|c|c|c|}
\hline Y1llar & $\begin{array}{c}\text { Önerilen } \\
\text { senaryo } \\
\text { (Mtoe) }\end{array}$ & $\begin{array}{c}\text { Tefek } \\
\text { vd. } \\
(2019) \\
\text { (Mtoe) }\end{array}$ & Y1llar & $\begin{array}{c}\text { Önerilen } \\
\text { senaryo } \\
\text { (Mtoe) }\end{array}$ & $\begin{array}{c}\text { Tefek } \\
\text { vd. } \\
(2019) \\
\text { (Mtoe) }\end{array}$ \\
\hline 2019 & 144.71 & 144.20 & 2025 & 175.00 & 175.9 \\
\hline 2020 & 149.71 & 149.00 & 2026 & 179.98 & 182 \\
\hline 2021 & 154.80 & 154.00 & 2027 & 185.01 & 188.2 \\
\hline 2022 & 159.93 & 159.20 & 2028 & 190.05 & 194.7 \\
\hline 2023 & 164.99 & 164.50 & 2029 & 195.08 & 201.5 \\
\hline 2024 & 170.00 & 170.1 & 2030 & 200.12 & 208.5 \\
\hline
\end{tabular}

\section{Sonuç}

Bu çalışmada, Türkiye'nin 1980-2030 yılları arasındaki enerji ihtiyac1, GSYİH, nüfus, ithalat ve ihracat değerleri kullanılarak modellenmiştir. Önerilen İF modeli, ort. RH, OKHK ve $\mathrm{OMH}$ açısından enerji tüketimini DF, EF ve HF' den daha iyi tahmin etmiştir. Bu nedenle senaryo analizinde Jaya algoritması ile eğitilmiş İF modeli kullanılarak, Türkiye'nin 2019-2030 yılları arasındaki enerji ihtiyacı tahmin edilmiştir. Bu çalışmaya göre Türkiye'nin 2030 yılındaki enerji ihtiyacının 200.12 Mtoe olması beklenmektedir. Analiz edilen senaryonun sonuçları Tefek vd. (2019) ile karşılaştırılmıştır. Tahmin edilen değerlerin yakınlığı modelin doğruluğunu artırmıştır.

Jaya algoritmasının sonuçları mevcut çalışmada tatmin edicidir. Bu nedenle, enerji kullanımını modellemek için Jaya algoritmasının kullanılması gelecekteki çalışmalar için tavsiye edilmektedir. 


\section{Kaynakça}

Boru Hatları ile Petrol Taşıma Anonim Şirketi (BOTAS). (2015). 2015 y1li faliyet raporu. https://www.botas.gov.tr/docs/raporlar/tur/sektorap_2015.pd f, (erişim tarihi:26.03.2021).

Bordbari, M.J., Seifi, A.R., \& Rastegar M. (2018). Probabilistic energy consumption analysis in buildings using point estimate method. Energy 142, 716-722.

Canyurt O.E., Ceylan, H. Ozturk, H.K. \& Hepbasli, A. (2004). Energy demand estimation based on two-different genetic algorithm approaches. Energy Sources 26,1313-1320.

Ceylan, H., \& Ozturk, H.K. (2004). Estimating energy demand of Turkey based on economic indicators using genetic algorithm approach. Energy Conversion and Management $45,2525-2537$.

Canyurt O.E., Ceylan, H., Ozturk, H.K., \& Hepbasli, A. (2004). Energy demand estimation based on two-different genetic algorithm approaches. Energy Sources 26, 1313-1320.

Ceylan, H., Ozturk, H.K., Hepbasli, A., \& Utlu, Z. (2005). Estimating energy and exergy production and consumption values using three different genetic algorithm approaches, part 2: application and scenarios. Energy Sources 27, 629639.

Ediger, V.S., \& Akar, S. (2007). ARIMA forecasting of primary energy demand by fuel in Turkey. Energy Policy 35:17011708.

Enerji ve Tabi Kaynaklar Bakanlığı (ETKB). (2019). http://www.enerji.gov.tr/File/?path=ROOT\%2f1\%2fDocume nts\%2fMavi\%20Kitap\%2fMavi_Kitap_2012.pdf, (erişim tarihi: 20.03.2021).

Kıran, M.S., Ozceylan, E., Gunduz, M., \& Paksoy, T. (2012). A novel hybrid approach based on particle swarm optimization and ant colony algorithm to forecast energy demand of Turkey. Energy Conversion and Management 53, 75-83.

Ozturk, H.K., Canyurt, O.E. Hepbasli, A., \& Utlu, Z. (2004). Residential-commercial energy input estimation based on genetic algorithm approaches: an application of Turkey. Energy and Buildings 36, 175-183.

Rao, R.V. (2016). Jaya: A simple and new optimization algorithm for solving constrained and unconstrained optimization problems. International Journal of Industrial Engineering Computations 7, 19-34.

Toksari, M.D. (2007). Ant colony optimization approach to estimate energy demand of Turkey. Energy Policy 35, 3984 3990.

Tefek, M.F., Uğuz H., \& Güçyetmez M. (2019). A new hybrid gravitational search-teaching-learning-based optimization method for energy demand estimation of Turkey. Neural Computing and Applications 31, 2939-2954.

Türkiye İstatistik Kurumu (TÜİK). (2019a). Nüfus ve demografi, nüfus istatistikleri. http://www.turkstat.gov.tr/UstMenu.do?metod=temelist, , (erişim tarihi:20.03.2021).

Türkiye İstatistik Kurumu (TÜİK). (2019b). İstatiksel tablolar, yıllara göre diş ticaret. http://www.turkstat.gov.tr/PreTablo.do?alt_id=1046, (erişim tarihi:20.03.2021).

Türkiye Cumhuriyeti Kalkınma Bakanlığı (TKB). (2019). Ulusal Gelir ve Üretim (Tablo 1). www.kalkinma.gov.tr, (erişim tarihi:19.03.2021).
Unler, A. (2008). Improvement of energy demand forecasts using swarm intelligence: The case of Turkey with projections to 2025. Energy Policy 36, 1937-1944. 